\title{
Community during the Pandemic and Civil Unrest
}

\section{Ronald E. Anderson ${ }^{1}$}

Received: 13 July 2020 / Accepted: 24 July 2020/Published online: 10 August 2020

(C) Springer Nature Switzerland AG 2020

\begin{abstract}
Beginning with the concept of community, this editorial describes the essence of community as connectedness, sharing and caring. The notion of cultural trauma helps clarify the meaning and impact of the pandemic and concurrent racial unrest. Evidence is offered of sharp decline in community wellbeing from these traumas. As in other major disasters, communities of support have arisen to help neighbors and others who need urgent assistance repairing their lives and their torn social fabric.
\end{abstract}

Keywords Community $\cdot$ Well-Being $\cdot$ Pandemic $\cdot$ Racism $\cdot$ Kindness $\cdot$ Trauma

The word 'community' appears in so many contexts that we tend to forget its essence for human beings. Community principally means bonds of interconnectedness made strong by sharing, commitments, coordination, caring and trust. Often the 'social fabric' metaphor is used to refer to the strength of these bonds among people in a community. The most human aspect of sharing is caring, as caring can be highly personal and intimate. Caring and kindness build even stronger bonds of cooperation and sharing. Discovering such bonds within a group signals most clearly that the group is a community. The roots of the word community include the Latin word 'communitas' and notions of shared equality. Etiologies of the word also tend to mention the phrase "public spirit," and sharing of goods and services. Sharing and caring relationships are much more common and pronounced in communities. Thus, kindness, generosity and altruism become more visible and feasible in communities.

\section{Pandemic and Racial Protests}

In early 2020, millions of communities were traumatized by the pandemic as deaths piled up, stoking fear of disease and deprivation. Amidst this uncertainty, the visuals of George Floyd's death on May 26 left people bewildered and sparked protests around

Ronald E. Anderson

rea@umn.edu

1 University of Minnesota, Minneapolis, MN, USA 
the world. Within only three weeks, protest demonstrations moved into over 2000 cities and towns in the United States and many more in over 60 additional countries. In the US, at least 200 cities had imposed curfews and at least 11,000 people were arrested, according to Wikipedia, which keeps a list of the protest locations.

As George Floyd took his last breaths, the viral video showed the police officer not only kneeling on Floyd's neck but enjoying the cruelty. It symbolized the complete absence of care and caring of white men toward black men. By mid-June additional cases of police brutality had become prominent in the media. They all implied black lives did not matter, which increasingly had become unacceptable. Gradually, the protests came to be labeled both the George Floyd and Black Lives Matter (BLM) protests. The leadership of the BLM movement helped focus protests on both police brutality and systemic racism.

\section{Cultural Trauma}

Sociologist Jeffrey Alexander (2004) introduced the theory of cultural trauma, defining it as a greatly disturbing and distressful event shared by a collectivity and which changes their identities in irrevocable ways. The pandemic produced a cultural trauma because not only did it force many disturbing lifestyle changes, but our identities became intertwined with the systems and leaders making public health policy. In countries like the US, where pandemic practice became politicized, people suffer additional trauma associated with their stands on such practices as the wearing of masks and social distancing. The specter of incompetent leadership unable to contain the virus added another type of trauma, to say nothing of isolation and severe financial distress, all of which in the US were borne much more heavily by the black and native minority communities.

The death of George Floyd and the protest marches around the world created a second cultural trauma. Unlike many shorter-term protest movements, this one produced greater support for taking action on police reform and reduction in institutional racism. Alexander (2020) argues that the enormous weight of the pandemic and the racial protests upon our pre-existing cultural traumas will lead us through a process of weighing competing narratives to determine responsibility for the conditions of the latest crises. He also speculates that both cultural traumas may not be resolved, leaving behind even greater holes in the social fabric over time.

\section{Coping with the Cultural Traumas}

Next, consider policy changes needed to reduce our cultural traumas from the pandemic and racial unrest. A useful way to frame the problem is: What can be done to restore trust at all levels of communities and societies? The pandemic is a public health problem, and so we need decision-makers who can make and execute wise public health policy and gain the trust of all citizens. Reducing the trauma of the racial protests requires a different set of priorities. Around the world, the protests call for radical reduction in racial discrimination at all levels of each community. Even countries lacking a long history of ethnic and racial strife, may suddenly face racial conflict. The best hope for curtailing the growth of racism and racial conflict is to ensure that racial tolerance is engrained into social institutions, especially legal, political and educational systems. 
In the United States, the most immediate need is to change the police culture in individual community police departments. It may be necessary to disband police departments and start over as did the Camden, NJ police department did in 2013. Community policing needs to be developed in all police departments in the US that don't already have it. For many police departments this will involve letting go many officers, hiring new officers and totally revamping police training. Extracting racism from police departments will not be enough. We also need to fix basic social problems such as failing schools and preschools in low income communities; generate lowincome housing solutions; create new job opportunities for minorities; and so on.

\section{Community Well-Being Plunged during the Pandemic}

Over the past decade, global well-being, as measured by the Gallup World Poll, has been mostly flat. With the global lockdowns this year, polling in many countries closed down too; thus, global estimates are not yet available. However, Gallup has released trends for the United States (Gallup 2020). The percent who said they "experienced anger most of yesterday" doubled (from 14\% to 28\%) in June of this year compared to 2015 , as did the percent feeling sadness. The rise in negative feelings of worry and stress did not double but rose substantially as well. Corroborating this rise in negative affect are the findings of the General Social Survey (NORC 2020), which has since 1972 been tracking happiness among Americans. During the pandemic, the percent who said they were "not too happy" jumped from $15 \%$ to $25 \%$, and the number "very happy" dropped from $31 \%$ to $14 \%$. This was the lowest level of American happiness in nearly 50 years.

The NORC also asked about isolation and loneliness; those who felt isolated jumped from $23 \%$ in 2013 to $50 \%$ in 2020 . Also, the number saying they "often lack companionship rose from $10 \%$ in 2018 to $18 \%$ in May 2020. This rise in loneliness and companionship undoubted contributed to the sharp fall in well-being.

The most serious evidence of pandemic degradation in community well-being in the US comes from the National Center for Health Statistics (NCHS) Early Release Program conducted by the U. S. Census Bureau. They found that $42 \%$ of adults in June 2020 "delayed getting medical care in the last four weeks but did not get it because of the coronavirus pandemic." This program also reported that $31 \%$ in June 2020 had either "an anxiety disorder or a depressive disorder." Respondents qualified as anxious or depressive only if they said they were anxious or felt little interest or pleasure in doing things for "more than half of the days over the past two weeks." From June 2019 to June 2020 the percent with such a disorder rose from 11\% to $31 \%$. This startling rise in self-reported mental health disorders suggests that the cultural traumas are deeper than many imagined (NCHS 2020).

Very similar estimates of anxiety during the pandemic were found in Britain in surveys done by their Office for National Statistics (ONS 2020). In a nationwide survey of 1900 randomly selected people during the second week of April, $48 \%$ reported "high anxiety levels," which dropped to $31 \%$ by the end of June. This reveals a very similar pandemic-linked mental health problem in the UK as in the US.

With respect to well-being more broadly, in the UK over half of adults (53\%) agreed with the statement "my well-being is being affected by COVID-19" in early April, and it dropped 
only slightly to $45 \%$ by late June. This implies that not only is the pandemic diminishing community well-being but that its effect remained fairly constant over the first four months of the pandemic. Assuming that these data from the US and the UK reflect the rest of the world, the pandemic has done havoc to global community well-being. Many countries have not been hit as hard by the pandemic as have the US and the UK, but most countries do not have the health facilities needed to care for a lot of cases. Furthermore, no one knows what the damage will be, were the pandemic to continue for years.

\section{Kindness during the Pandemic}

In the early days of the pandemic, newspapers and other media frequently carried stories of how people had gone out of their way to be kind to others. In July of 2020, I Googled 'pandemic kindness' and got 39 million hits. Also, I found thousands of newspaper stories about kindness during the pandemic. Surveys are a better way to gage kindness. The best surveys on this were done in Britain by their Office for National Statistics (ONS 2020). In their first wave in April 2020, 78\% agreed "people are doing more to help others since the coronavirus outbreak." Of those surveyed, $75 \%$ said he or she had checked on their neighbors at least once, while almost a half (49\%) said they had helped someone who lived nearby by shopping for them, walking their dog or something similar (ONS 2020). These three questions were repeated three months later, and the percentages had dropped only about $10 \%$. Also the UK survey found that $10 \%$ of adults reported caring for a "sick, disabled or person over 70 in their home." These statistics together suggest that kindness is a part of the social fabric of every community's response to a pandemic.

Evidence of British caring and compassion during the pandemic was found in another UK survey by Populus (2020). In early April they surveyed 2093 persons asking them to rank their top three values out of the following list of nine attributes: "good judgment, being reflective, being compassionate/caring, courage, community awareness, service to others, resilience, motivated, and wisdom." The most valued of these character qualities was "compassionate/caring." When asked to give their most valued qualities for "leaders/senior political figures," the highest valued was "good judgment," but compassionate/caring was next highest. So, even for political leaders, compassion and caring were deemed extremely important. In an earlier article, I urged community researchers to look to compassion and caring as a core aspect of community solidarity (Anderson 2017). The pandemic reinforces that position.

\section{Disaster Brings out the Best}

Sometimes cultural traumas bring out the worst in people. Looting and burning of buildings began two days after George Floyd's killing. And some people defied the pandemic by packing into crowded bars. Ironically, cultural traumas also produce outpourings of positive deeds and feelings. Disaster researchers have long wondered about the implications of the idiom "all in the same boat," and why it evokes a drive to help each other out. Apparently, the idiom originated with the ancient Greeks and the need to remind everyone in a shipwrecked little boat 
that it does no good to complain. Instead, crisis gives everyone an incentive to contribute to the common good. After studying the five worst natural disasters since 1900, Solnit (2010) wrote "disasters require us to act, and act altruistically, bravely, and with initiative in order to survive or save our neighbors, no matter their wealth or how they vote.

Legendary psychologist William James (1911) visited the great 1906 earthquake that destroyed San Francisco and was so impressed by the positive attitude of the survivors that he wrote "a civic temperament of social engagement ... and extraordinary selflessness, heroism, transcendence, and sacrifice" were created by the disaster. One of the early pioneers of disaster research, sociologist Charles Fritz (1961), headed a team of 25 researchers at the NORC at the University of Chicago. Together they extracted conclusions from 9000 interviews across 700 disaster sites. Fritz concluded that a major catastrophe produces a "community of sufferers" that allows individuals to experience an immensely reassuring feeling of connection to others. He believed this feeling of "being in the same boat" was also made possible by the utopian idea of freedom from differences in social status. After reviewing this research, Bregman (2020) concluded that major social crises tend to produce altruistic behaviors that by far outweigh any of the negative outcomes.

I live ten miles from where George Floyd was murdered, and 1500 buildings were burned down in two days in May. It felt like a disaster zone. But the days immediately thereafter also felt like renewal. Even as thousands joined the marchers, hundreds moved among the shop-owners to help them pick up trash, sweep the sidewalks, wash off the graffiti, board up windows, and supply the grievers with food and shelter. Many local volunteers also helped coordinate the marching to minimize violence and injury. Two months after the riotous protests, a GoFundMe site surpassed \$15 million for the rebuilders. The spirit of goodness still can be seen at work as neighborhood groups, local churches, and nonprofits continue to work hard for those in need of help in rebuilding, as well as programs supplying food and other assistance in low income neighborhoods.

\section{Conclusion}

The cultural traumas of the pandemic, and to some extent the unrest over racism, likely have devastated global community well-being, Already the world news has given us a portrait of grave differences in communities and countries in their resilience to respond to the pandemic. Hopefully, research on community resilience will help even more communities protect themselves from the spread of the Coronavirus. The pandemic indirectly makes a case for building resilience and solidarity through compassion and caring. The upswing in kindness is one of the few rays of light and hope in this challenging time.

\section{Compliance with Ethical Standards}

Conflict of Interest None. 


\section{References}

Alexander, Jeffrey C. (2004) Cultural trauma and collective identity. Univ. of California Press.

Alexander, Jeffrey C. (2020). Yale's Jeffrey Alexander on how today's crises might shape tomorrow. YaleNews (June 20), pp 1-7.

Anderson, R, E. (2017). "Community functioning that fosters sustainable social well-being. Pp. 3-10 in Handbook of Community Well-Being Research, springer.

Bregman, Rutger (2020). Humankind: A history of Hope. Little, Brown \& Co.

Fritz, C. (1961). Disasters and mental health: Therapeutic principles drawn from disaster studies. Newark: University of Delaware Disaster Research Center.

Gallup. (2020). In U.S., Negative Emotions Surged, Then Declined in June. https://news.gallup. com/poll/312872/negative-emotions-surged-declined-june.aspx. Accessed 22 Jun 2020.

James, W. (1911). Memories and studies. Green: Longmans.

NCHS (2020). Mental health household pulse survey. Centers for Disease Control and Prevention. Accessed on 4July2020 at https://www.cdc.gov/nchs/covid19/pulse/mental-health.htm

NORC. (2020). Covid response tracking study. National Opinion Research Center: University of Chicago.

ONS (2020). Opinions and lifestyle survey. Office for National Statistics. https://www.ons.gov.uk/

Populus. (2020). Character in crisis survey. Jubilee Centre for Character and Virtues: University of Birmingham Accessed at https://www.jubileecentre.ac.uk/media/news/article/6695/Polling-ShowsBritish-Public-Still-Value-Compassion-in-Others-but-Place-Less-Value-on-Civic-Virtues.

Solnit, R. (2010). A paradise built in hell: The extraordinary communities that Arise in disaster. Penguin Books.

Publisher's Note Springer Nature remains neutral with regard to jurisdictional claims in published maps and institutional affiliations. 